\title{
Estudo teórico da adsorção de gás de síntese em MgO e ZnO
}

\author{
*Rogério J. Costa ${ }^{1}(\mathrm{PG})$, Elton A. S. Castro²(PQ), João B. L. Martins ${ }^{1}(\mathrm{PQ})$. \\ rogerquim@gmail.com \\ ${ }^{1}$ Universidade de Brasília \\ ${ }^{2}$ Universidade Estadual de Goiás
}

\begin{abstract}
RESUMO
O estudo das reações químicas de superfícies tem se mostrado de interesse para muitas áreas da ciência e setores ligados a indústria, saúde pública, meio ambiente e também na busca de fontes de energia alternativa. A reatividade pode ser compreendida no processo de adsorção envolvendo adsorventes e adsorbatos, onde diversas informações podem ser obtidas por estudos químico computacionais. A separação de gases oxigênio, hidrogênio, monóxido de carbono, dióxido de carbono e água podem ser alcançadas com o uso de catalisadores a base de óxido de magnésio e de óxido de zinco. Neste trabalho teórico, foram realizados cálculos mecânico-quânticos com modelos envolvendo as interações de gás de síntese com as superfícies de $\mathrm{MgO}$ e $\mathrm{ZnO}$ em que propriedades eletrônicas e estruturais destas interações serão apresentadas e discutidas.
\end{abstract}

Palavras-chave: Adsorção. MgO. ZnO. Gás de síntese.

\section{Introdução}

A evolução da sociedade moderna vem dependendo da disponibilidade de recursos energéticos e uma multiplicidade de produtos químicos. As reservas fósseis tem fornecido ao longo dos anos uma considerável quantidade de matéria-prima, as quais são indispensáveis para a manutenção da vida humana. As pesquisas em catálise heterogênea envolvendo o processo de adsorção em superfícies de óxidos metálicos como o óxido de magnésio e o óxido de zinco tem sido intensa devido à sua potencial aplicação em processos ocorridos no meio ambiente. ${ }^{1}$

A separação de gases, do chamado gás de síntese, como o hidrogênio $\left(\mathrm{H}_{2}\right)$, oxigênio $\left(\mathrm{O}_{2}\right)$, monóxido de carbono $(\mathrm{CO})$, dióxido de carbono $\left(\mathrm{CO}_{2}\right)$ e água $\left(\mathrm{H}_{2} \mathrm{O}\right)$ são amplamente realizadas por catalisadores a base de óxidos como o óxido de magnésio $(\mathrm{MgO})$ e o óxido de zinco $(\mathrm{ZnO}){ }^{2,3}$ A identificação e separação destas moléculas são de extrema importância, uma vez que o uso de reagentes com elevado grau de pureza é de grande valia para a qualidade dos produtos e materiais fabricados nas indústrias em geral. Em procedimentos hospitalares o $\mathrm{O}_{2}$ é fundamental e, por outro lado, o $\mathrm{CO}$ e o $\mathrm{CO}_{2}$ em elevada proporção pode ser extremamente prejudicial ao ser humano e ao meio ambiente. ${ }^{4,5}$

\section{Metodologia}

Foram utilizados métodos UFF, PM6 e DFT com os funcional B3LYP, com as funções de base 6-31+G(d) e 6-31+G(d,p) aplicados em conjunto no método híbrido ONIOM (Our own Nlayered Integrated molecular Orbital and molecular Mechanics). Este é sofisticado método que possui como uma das principais características a possibilidade de trabalhar-se com sistemas de grande tamanho utilizando diferentes métodos de teorias em diferentes locais da estrutura. A otimização visou o relaxamento de centros pentacoordenados no $\mathrm{MgO}$ (Figura 1-b) e hexágonos no $\mathrm{ZnO}$ (Figura 1-d) com os gases do gás de síntese. 


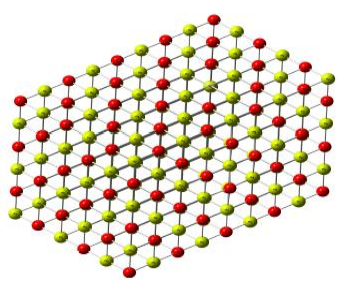

(a)

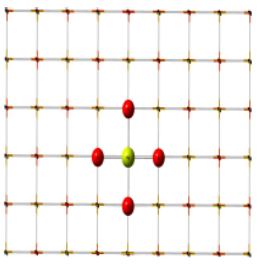

(b)

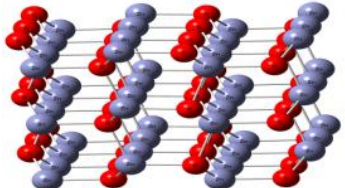

(c)

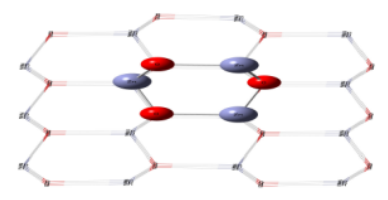

(d)

Figura 1. Modelos de $\mathrm{MgO}$ e $\mathrm{ZnO}$ com destaque para os centros penta-coordenados (b) e hexágonos (d).

\section{Resultados e Discussão}

As energias de ligações foram calculadas através das diferenças das energias totais dos complexos otimizados e suas respectivas partes isoladas e otimizadas dispostas para os grupos de modelos calculados com ONIOM, bem como frequências calculadas após o processo de otimização. Distâncias, ângulos e outras informações de geometrias também foram analisados.

\section{Considerações Finais}

Os níveis teóricos utilizados para os cálculos dos complexos de $\mathrm{MgO} / \mathrm{Gás}$ de síntese e $\mathrm{ZnO/Gás} \mathrm{de} \mathrm{síntese} \mathrm{próximos} \mathrm{aos} \mathrm{centros} \mathrm{penta-coordenas} \mathrm{e} \mathrm{hexágonos} \mathrm{tem} \mathrm{se}$ mostrado eficientes com resultados de geometrias e energias próximos de trabalhos teóricos e experimentais da literatura. O método ONIOM(PM6:UFF) vem mostrando tendências de aumento de energias de ligação com o aumento de centros da camada alta liberados para otimização e pares de átomos no hexágono central do $\mathrm{ZnO}$, bem como as geometrias das moléculas de gases nas superfícies estão em concordância com dados teóricos e experimentais.

\section{Agradecimentos}

FAPDF, CNPq, CAPES

\section{Referências}

[1] Y. Xu, J. Li, Y. Zhang, W. Chen. Surface science, vol. 525, no. 1, pp. 13-23, 2003.

[2] D. Rethwisch, J. Dumesic. Applied catalysis, vol. 21, no. 1, pp. 97-109, 1986.

[3] Ü. Özgür, Y. I. Alivov, C. Liu, A. Teke, M. Reshchikov, S. Dogan, V. Avrutin, S.-J. Cho, H. Morkoc. Journal of applied physics, vol. 98, no. 4, p. 11, 2005.

[4] M. J. Gradassi, N. W. Green Fuel Processing Technology, vol. 42, no. 2-3, pp. 6583, 1995.

[5] O. Karalti, D. Alfe, M. J. Gillan, K. D. Jordan. Physical Chemistry Chemical Physics, vol. 14, no. 21, pp. 7846-7853, 2012. 